Reprod. Nutr. Dévelop., 1987, 27 (1 B), 246-248.

\title{
Etude microscopique de la digestion des parois végétales des téguments de soja et de colza dans le rumen
}

Elisabeth GRENET, P. BARRY

Laboratoire des Aliments,

I.N.R.A. Theix 63122 Ceyrat, France.

Summary. The rumen microbial digestion of two by-products, soyabean hulls (cell walls composed mainly of cellulose and hemicelluloses) and rapeseed hulls (highly lignified cell walls), has been observed by light microscope and scanning electron microscope.

L'importance et la vitesse de la digestion des parois végétales par les microorganismes du rumen dépendent fondamentalement de la composition de ces parois, en particulier de leur lignification. A l'aide de la microscopie photonique (MP) et de la microscopie électronique à balayage (MEB) nous avons étudié la digestion dans le rumen de deux sous-produits : le tégument de soja, particulièrement riche en parois (hémicelluloses 20,8 , cellulose 43,5 et lignine $1,6 \%$ de la matière sèche), et le tégument de colza, dont les parois sont très lignifiées : hémicelluloses 14,6 , cellulose 16,2 et lignine $18,1 \%$ de la matière sèche, selon la méthode de Van Soest (Chapoutot, communication personnelle).

Matériel et méthodes. Dix fragments de téguments de soja (G/ycine max L.) et de colza (Brassica napus $L$.) prélevés manuellement sur des graines destinées à l'alimentation animale, ont été introduits dans des sachets de nylon. Ces sachets ont été placés avant la distribution du repas, pendant $4 \mathrm{~h}, 8 \mathrm{~h}, 16 \mathrm{~h}, 24 \mathrm{~h}, 48 \mathrm{~h}$ et $72 \mathrm{~h}$ dans le rumen de moutons fistulisés alimentés avec du foin de luzerne. Après leur sortie du rumen, les échantillons ont été fixés dans la glutaraldéhyde et pour moitié séchés au point critique avant observation au MEB, et pour l'autre moitié inclus dans la résine; des coupes de 3 microns ont été réalisées et colorées à la safranine et au vert rapide ainsi qu'au phloroglucinol-chlorhydrique. De plus des observations ont été réalisées en fluorescence dans l'ultraviolet.

Résultats et discussion. Le tégument de soja est constitué de l'extérieur vers l'intérieur de plusieurs couches cellulaires (photo 1, de haut en bas), I'assise palissadique (Apa), l'assise des sabliers (As), le parenchyme (P) et l'assise protéique (Ap) (Juillet et al., 1955). Les colorants utilisés ainsi que les observations en fluorescence ne mettent pratiquement pas en évidence de parois lignifiées, ce qui confirme les résultats des analyses chimiques. La digestion de $\mathrm{P}$ libère la base de As au bout de $8 \mathrm{~h}$ de séjour. Celle-ci est ensuite progressivement digérée et Apa est alors attaquée par les microorganismes au bout de $24 \mathrm{~h}$ de séjour et est presque totalement digérée au bout de $72 \mathrm{~h}$ (photo 2). Nous avons observé que des bactéries, des protozoaires mais aussi de nombreux champignons anaérobies du rumen participent à cette digestion. Les photos 3 et $\mathbf{4}$ montrent les sporanges de ces champignons dont les enzymes hydrolytiques, vraisemblablement situées dans les rhizoïdes, doivent dégrader les hémicelluloses et la cellulose.

Le tégument de colza comporte de l'extérieur vers l'intérieur (photo 5 , de haut en bas) l'épiderme (E), l'assise scléreuse (Ascl), I'assise brune (Ab), l'assise protéique ( $A p$ ) et l'assise hyaline (Ah). Les techniques utilisées mettent en évidence une importante lignification de Ascl. Au bout de $8 \mathrm{~h}$ de séjour dans le 
rumen Ah est digérée et la partie interne de Ap commence à être attaquée. Ap est presque totalement digérée au bout de $48 \mathrm{~h}$; seule la base des cellules contigue à Ascl reste intacte, de même que Ascl qui n'est presque pas digérée même au bout de 72 h (photo 6 ). Nous n'avons observé ni protozoaires, ni champignons sur ces téguments : seules des bactéries étaient fixées aux parois.
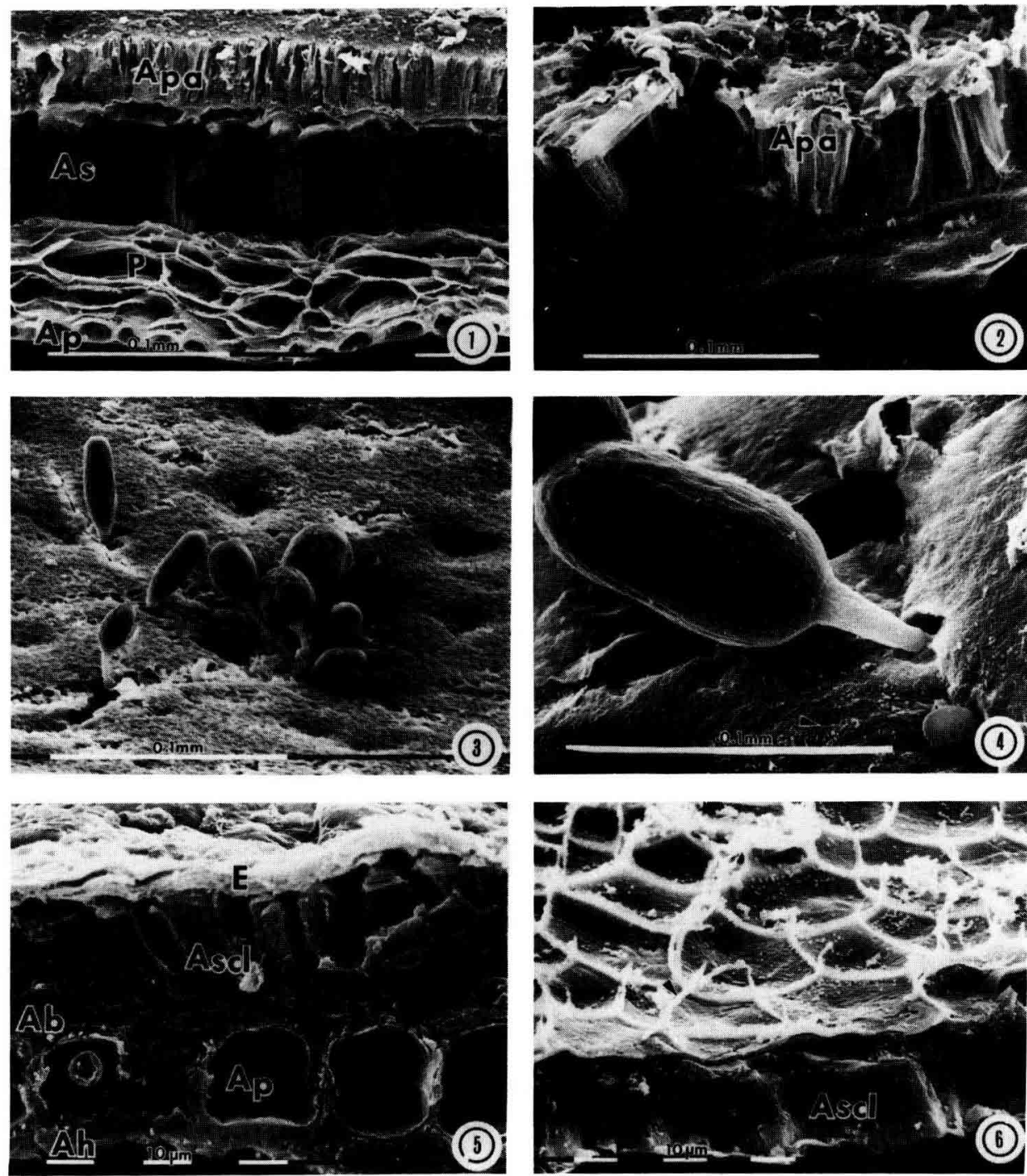

Photo 1. - Coupe transversale d'un échantillon témoin de tégument de soja $(\times 400)$. Photo 2 . Echantillon de tégument de soja ayant séjourné $72 \mathrm{~h}$ dans le rumen. Les cellules de l'assise palissadique (Apa) sont partiellement digérées $(\times 400)$. Photo 3. - Sporanges de champignons anaérobies du rumen colonisant le tégument de soja. 16 h de séjour dans le rumen $(\times 550)$. Photo 4 . - Sporanges de champignons anaérobies du rumen colonisant le tégument de soja. 24 h de séjour dans le rumen $(\times 750)$. Photo 5. - Coupe transversale d'un échantillon témoin de tégument de colza $(\times 1200)$. Photo 6. - Echantillon de tégument de colza ayant séjourné $48 \mathrm{~h}$ dans le rumen. L'assise sciéreuse (Ascl) est intacte et l'assise protéique est presque totalement digérée $(\times 1000)$. 
Ces observations mettent en évidence le rôle de la lignine dans la digestion des parois par les microorganismes, du rumen. Elle constitue un obstacle à la dégradation enzymatique. Nous avons pu remarquer d'ailleurs que très peu de bactéries sont fixées sur l'assise scléreuse du tégument de colza contrairement aux autres assises cellulaires. Ceci confirme les résultats obtenus par Guillon (1984) sur d'autres sous-produits peu lignifiés comme le son de blé ou le tégument de lupin, ou très lignifiés comme le tégument de tournesol.

Guillon F., 1984. DEA de Biologie et Physiologie Végétales Appliquées aux Ressources Agricoles et Alimentaires (Univ. de Nantes).

Juillet A., Susplugas J., Courp J., 1955. Les oléagineux et leurs tourteaux. Ed. Lechevalier, Paris. 